\title{
HISTRIONIC IMMATURE PERSONALITY DISORDER
}

\author{
Simona Trfiu ${ }^{* 1}{ }^{\circledR}$, Elena-Alexandra Neacșa ${ }^{2}$, Ștefania-Elena Neagoe ${ }^{3}$, \\ Andreea-Simina Ojică ${ }^{4}$ \\ *1 University of Medicine and Pharmacy "Carol Davila”, Bucharest, Romania \\ 2 Faculty of Pshychology and Education Science, University of Bucharest, Romania
}

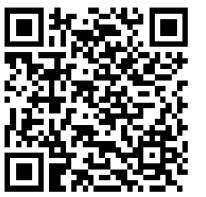

DOI: https://doi.org/10.29121/granthaalayah.v9.i3.2021.3801

Article Type: Research Article

Article Citation: Simona Trfiu, Elena-Alexandra Neacșa, Ștefania-

Elena Neagoe, and Andreea-Simina

Ojică. (2021). HISTRIONIC

IMMATURE PERSONALITY

DISORDER. International Journal of

Research -GRANTHAALAYAH, 9(3),

241-247.

https://doi.org/10.29121/granthaa

layah.v9.i3.2021.3801

Received Date: 09 March 2021

Accepted Date: 31 March 2021

Keywords:

Histrionic Personality Disorder Dissociative/Conversion Disorder Immature Personality

Sensitivity Oedipus Complex

\begin{abstract}
Background: We aim at presenting a clinical case of a 37-year-old patient, who has been a nun for several years and at the moment can no longer adapt to the environment in which she lives and to the requirements of everyday life. The perspective of this analysis is both a psychiatric one, explaining the diagnosis of Axis II of Histrionic Immature Personality Disorder, but also the overlap with dissociative conversion disorder, and explanatory from a psychodynamic perspective, by addressing the regression issues and the presence of the Oedipus Complex.

Histrionic Immature Personality Disorder and its overlap with Dissociative/Conversion Disorder are conditions with negative effects in terms of adaptation to the social environment and assuming professional responsibilities. Also, the particularities in the sphere of immaturity make it difficult to relate to those around.

Method: Hospitalization, psychiatric interview, psychodynamic interview, psychological tests - CAQ Personality Questionnaire and the Szondi Test, psychodynamic interpretations.

Results: The results highlight aspects of an immature premorbid personality, characterized by a high degree of sensitivity. Currently, the patient's ego is fragile and cannot adapt to the emotional meanings in the environment in which she lives, which leads to functional crises and manifestations such as dissociative fugue.

Conclusions: Dissociative manifestations are associated with immaturity and reduced ability to adapt to professional requirements. On a personal level, the same immaturity leads to the denial of one's sexuality and projection.
\end{abstract}

\section{INTRODUCTION}

\subsection{REASONS FOR ADMISSION}

The 37-year-old patient was hospitalized because she passed out whilst she was in a store, an incident that has happened in the past and which is justified, from her point of view, by the fact that her relationship with the nuns from the monastery where she was living is a strained one.

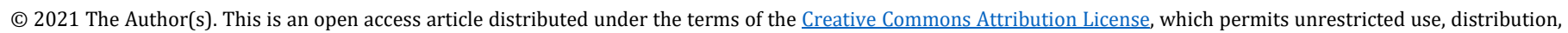
and reproduction in any medium, provided the original author and source are credited. 
Histrionic Immature Personality Disorder

Sometime before the patient suffered a psychotic episode whilst she was on a trip to The Church of the Holy Sepulchre in the Christian Quarter of the Old City of Jerusalem, where she experienced feelings from the sphere of the dissociative trance and possession disorder - she fainted, claimed that the Holy Spirit possessed her body and her manner of speaking indicated that she was communicating with a spiritual entity.

Thus, the patient is checked into a psychiatric ward due to memory loss, instant fainting and suicide attempts, all of which are contained by the sensitive dimension of her personality.

At the same time, she is not aware of her own behavioural problems.

\subsection{PERSONAL HISTORY}

Her education consists of eleven years of school and she says that she regrets not having had received a higher education, because she was too afraid to.

Prior to hospitalization, she had lived in a monastery since 2001, her intention was to enter such an institution from her own initiative, claiming that her wish was not influenced by anyone, ever since childhood, from the age of 12 , but she had to postpone this decision in order to continue her schooling.

The patient claims that her mother was physically assaulted by the patient's grandmother, which determined the patient's mother to leave home at 18 years old. She gave birth to a daughter shortly after leaving home (the patient's older sister), but the child was ill and remained in hospital due to complications, the patient's mother leaving for Bucharest, where she became pregnant again. When the patient was 13 and a half years old, her mother received a phone call that informed her that she had to start taking care of her first daughter, Adriana, who was then 18 years old. At the time of the interview, the patient claims that her mother's third husband, the current stepfather, loves both girls and that their family life together had been a joyful one. There are no reports of the biological father.

She has lived in several monasteries, because she encountered difficulties in terms of integration into the social environment there, confessing that "she had trials in the monastery, quarrels, temptations".

In 2005 she was involved in a car accident about which she does not remember certain moments, she was unconscious and underwent neurosurgery.

\subsection{PREMORBID PERSONALITY CHARACTERISTICS}

The patient's accentuated sensitivity stands out, which influences her opinions about the events in her life and the way she perceives other people's motivations. In this sense, in connection with the social environment within the monastery, she says that "envy and pride are at work". At the same time, she has a very good opinion about herself and about other people's perceptions of her, saying that she is doing very well and that she is appreciated by Christians for her vocal and housekeeping qualities.

Furthermore, her sensitivity is illustrated by her perception of the doctor who treated her after the car accident, claiming that she "felt" his harshness. Also, she considers the doctor to be "heretical" because that's what the women around him told him. In addition, she claims that the abbess who accompanied her to the hospital had discussions with the doctor about the patient's behavioural aspects about which she is dissatisfied, considering the doctor's attitude influenced by her.

Regarding the life in the monastery, the patient considers herself a victim and is dissatisfied with the fact that she remained a "sister" in the church hierarchy, which is the lowest position one can have, having the same status since entering this community in spite of her qualities. Thus, in order to improve this aspect, the patient seeks to constantly improve in music and household chores.

Also, after the accident, the patient suffered physical injuries as a result of which she could no longer maintain the household activities at the monastery, being accused of pretending to avoid work.

\section{MATERIALS AND METHODS}

The first method used was hospitalization, where she was administrated a series of medication to sustain her state of consciousness. The psychiatric interview, accompanied by the psychodynamic one, have constructed the overall picture of the patient's state. Furthermore, CAQ Personality Questionnaire and the Szondi Test have been used. All of the above evaluations have consisted of psychodynamic interpretations. 
Suicide Attempt - she has had two suicide attempts in the past, the first time the patient self-administered a teaspoon of caustic soda and the second time she wanted to jump off rocks, in both cases she says she was influenced by instant thoughts that seemed bizarre and which she did not have before the car accident which occurred in 2005 , because "she did not agree with such a thing". She confesses that she had "a little bit of discernment" because the first time the gesture was not a total one, and the second time she did not put her thoughts into action, because the fear of death stopped her.

Functional Crises - feelings of depersonalization and derealization, the patient loses consciousness when she is in life situations in which she does not feel comfortable, not being aware of the reasons that generate dissatisfaction.

Memory Loss - after the accident, the patient began to have memory loss, especially when she is upset by someone. She claims that during a telephone conversation she did not know anything about the family she was talking to for a few minutes, even though they were her acquaintances. At the same time, she no longer recognized the people she knew, shortly before the moment of hospitalization.

Dissociative Amnesia - elective, affectogenic amnesia, the patient forgets moments characterized by an intense negative emotional tension.

Suggestibility - dissociates easily, is influenced by the emotional state of the ones surrounding her.

Sensitivity - is easily affected by other people's reactions, interprets that they are directed at her.

Immaturity - attachment to a fifth-grade poem and identification with the character presented, who is a child; the desire to be the centre of attention, to showcase her talents; non-compliance with the rules of the monastery under the influence of immature mechanisms.

Denial of one's sexuality and Projection - she has the pleasure of watching actors, scientists, like a 15-yearold girl who falls in love with the image of a famous person. She has a fixation on the abbot whom she knows from the monastery. During the hospitalization caused by the accident, she had an interaction with another patient, whom she later accused of manifesting inappropriate sexual behaviours towards her, despite the fact that she was the one who caused the event. The patient experiences derived pleasures which are bothering the ones surrounding her.

Delusions of Grandeur - the other nuns "are not like me", "and the others have a penchant for music, but not like me", she considers herself to be "the best in the monastery", she claims that she has the ability to "tell someone personality by his face", she also presents herself as having a "special relationship with God".

\section{Positive Diagnosis}

Considering the above symptoms, it is argued that the diagnosis of Axis II is Immature Histrionic personality disorder which overlaps with Conversion disorder.

This psychological diagnostic is included in hysteria concept described by Charcot. This diagnostic is structured on three fundamental ideas. Firstly, the concept of hysteria as a personality structure can be observed, the patient being a histrionic woman (she shows demonstrative suicide attempt, but, in fact, not wanting to harm herself). Secondly, the neurotic register is remarked through conversion disorder, somatization disorder or dissociative disorders (multiple personalities, dissociative amnesia, depersonalization-derealization disorder). Lastly, the pathology can be described through hysterical psychosis, manifested through mass disorder and possession.

The Immature personality disorder is included in the category of Other specific personality disorders (F60.8) from ICD-10 The classification of mental and behavioural disorders. The dedicated section of the disorder mentioned above does offer neither a conceptualization, nor the specific symptoms of the Immature personality disorder. Furthermore, this personality disorder is neither specifically detailed in The Diagnostic and Statistical Manual of Mental Disorders (DSM-V). 
However, the patient's immature behaviour can be linked to the attachment towards a poem from the $5^{\text {th }}$ grade and her strong identification with the main character presented in it, a child. Furthermore, the patient described in this paper is always seeking attention, and she is always willing to show her talents off. Not least, the influence of the immature mechanism is also visible in her disobedience of the monastery's rules.

The Histrionic personality disorder (F60.4) is included in the category of Specific personality disorders (F60) from ICD-10 The classification of mental and behavioural disorders. Specific personality disorder can be characterized by a severe disruption of the behavioural tendencies, including several areas of the personality, in association with personal and social disruption.

Histrionic personality disorder is characterized by self-dramatization, exaggerated and theatrical expression of emotions, high suggestibility, the patient is almost always influenced by the people around her, labile and superficial affectivity, sensation seeking, the desire to be the centre of attention, always appreciated by the other, inappropriate behavioural and guise seduction, exaggerated attention to the physical attraction. Suggestible structures- the patient is easily dissociable, takes over the emotional state of the entourage.

The patient's behaviour described in this paper meets the necessary criteria to be included in the category of the histrionic personality disorder. Thus, her seeking attention desire can be characterized by two suicide attempts. The woman's grandeur and validation tendency can be illustrated by her cognitions about the other nouns around her, calling them "not like her". Also, the patient is characterized by a suggestible structure, being easily influenced: she is easily dissociable, takes over the emotional state of the entourage and is she affected by other peoples' reactions, thinking that they are directed towards her.

Conversion disorder (F44), as is described in ICD-10 The classification of mental and behavioural disorders represents a partial or total loss of a normal integration between the memories of the past, identity and sensations awareness and the control of body movements. The term "conversion" illustrates that a negative affect, generated by problems and conflicts which the person could not handle, is transposed into specific symptoms and behaviours.

Dissociative disorders are characterised, according to Diagnostic and Statistical Manual of Mental Disorder $(D S M-V)$, through a fragmentation and/or discontinuity regarding normal integration of conscience (psychic reflection of objective reality), memory, identity, emotion, perception, corporal representation, motor control and behaviour. Dissociative symptoms found in patient's case are felt in two manners. The first one refers to experiencing spontaneous bothering events in her conscious state and behaviour. These are associated with the loss of subjective experience (for example, her second suicide attempt). The second one is manifested through the inability of reaching information or controlling mental functions that are, normally, immediately available for accessing or controlling (for example, forgetting details about the family she is talking on the phone with). Dissociative disorders appear frequently in a short period after a trauma, being associated, in the patient's case, with her car accident.

In the case of Conversion disorder, the patient manifests a series of functional crisis, represented by sudden falls, fainting, depersonalization feelings and derealization, temporary loss of memory. These are generated by the life situations the patient finds herself in and she does not feel comfortable in the context. She does not realise the fact that she is in disagreement with the particularities of the surrounding environment.

Thereby, the woman described accuses symptoms that can be included in Dissociative amnesia (F44.0), disorder which can be described by the loss of the memories of certain traumatic events, not due to an organic mental disorder, forgetfulness or fatigue, but due to psychiatric causes. Likewise, forgetfulness is partial and selective, varying between examination times or from one day to another. The emotional states which are met in the dissociative amnesia can vary from perplexity, discomfort, to even seeking attention behaviours. The patient described is usually having loss of memories characterized by negative emotional tension. According to Diagnostic and Statistical Manual of Mental Disorder (DSM-V), dissociative amnesia is characterised through patient's incapacitation of rememorising autobiographical information. The amnesia can be localized (for example, the forgot events from the car crash), selective (for example, forgetting details regarding the family she was talking on the phone with) or generalized (for example, the moments in which she forgot the persons she usually had to know). This can lead to planned or meaningless travels (for example, the brake away from the monastery).

In addition to those presented above, the patient meets the criteria necessary to be included in the Dissociative fugue state (F44.1), being a facet of dissociative amnesia, according to the fifth edition of the Diagnostic and Statistical Manual of Mental Disorder (DSM-V). This includes flight, leaving apparently without a well-established purpose in a certain place, time in which self-care is maintained. This departure can also be doubled by a new identity that can last starting from a few days up to longer periods of time. In the case presented, the patient suffered a psychotic episode in which she went on a trip to the Holy Sepulchre, a place with a strong emotional charge, in which she 
experienced feelings in the sphere of trance and possession disorder - she fainted, claiming that the Holy Spirit entered her, her speech indicating that she would communicate with a spiritual entity.

The psychotic episode described above can be included in the sphere of possession trance disorder (F44.3), a disorder that involves a temporary loss of a sense of personal identity and full awareness of the environment. In these moments, the person can act as she is possessed by another personality, spirit, entity. According to the Diagnostic and Statistical Manual of Mental Disorder (DSM-V), dissociative trance resembles a disorder that is characterised through sudden shrinking or complete loss of conscience regarding her close surroundings. This manifests through a complete lack of responsiveness or insensibility regarding surrounding stimuli. These can be accompanied by minor cases of stereotypical behaviour, transitory paralysis or conscience loss. These particularities are met in the patient's behaviour while visiting the Holy Sepulchre, where she manifested states of trance and possession. The patient states that Holy Grail descended into her, making her able to communicate with the divinity. She was writhing and she thought she was in other dimension, the whole event lasting approximately one hour, including all psychic feelings that followed.

Personality disorders represent a change in some personality structures that have been shaped over time and these cannot be changed by psychological interventions. However, the problematic structures can be kept under control and guided by adaptive cognitive and behavioural responses. Thus, the gold standard intervention in treating personality disorders is represented by psychotherapy, the supportive and psychodynamic therapy are also being considered some of the most effective forms (French \& Shrestha, 2019). Thereby, our patient can be recommended several therapy sessions in order to improve personal and social behaviour.

\section{RESULTS AND DISCUSSIONS}

\subsection{PSYCHOLOGICAL EXAMINATION}

Psychological examinations taken by the patient confirm immaturity and histrionics.

The personality questionnaire CAQ seeks the measurement of normal personality features and the parameters of clinical factors. Regarding her personality features, the patient scored maximum $(T=10)$ on the next facets: Conformism, Eccentricity/Extravagance, Sensitivity, Radicalism, Tension. This shows the features of her personality and the fact the patient is governed by sensitivity, by being suggestible and deeply immature at an emotional level. Personality structures specific to hysteria can be found, through which the patient assumes the emotional state of the others in order to build her own ego. By analysing the dimension of the clinical factors, the patient got the highest score for facet Hypochondria ( $T=10)$, followed by Agitation and Psychopathic Deviation ( $T=9)$. This supports the diagnostic of disorder and dissociative conversion, where the somatization disorders are active. The dynamics between mental and somatic are encountered, feelings being experienced in her body rather than her soul.

Furthermore, the Szondi test was given to the patient in order to measure the tension and valence of the compulsions, allowing the knowledge of deep motivations that represents the basis of behaviour. Thus, the Sexual Compulsion vector $(S)$ indicates a histrionics symptomatology. The result points a weak and passive genitality, with abstinence or periodical frigidity, suggesting a secondary erotism expressed by tactile voluptuousness. The sexuality is infantile, proving the subordination character of the erotic-sentimental bonds. Regarding the proximal vector of Surprising Compulsions ( $P$ ), the patient can be described through lamentable theatrical behaviour (whiny). This masks well the situational emotions and the bizarre sexual tendencies. The Ego Compulsions vector (Sch) determines a suppressed ego of the patient that impulsively orients herself with weakly acknowledged actions. The patient possesses the favourable particularities of interaction with the occupational therapy field. The fourth vector, Contact Compulsions (C), shows the patients character as unstable and easily seduced in environmental relations. She manifests an oriented polyform interest (infantile), being extremely curious. Her symptomatology spectre integrates the histrionics dimension.

\subsection{PSYCHODYNAMIC INTERPRETATIONS}

International Journal of Research -GRANTHAALAYAH 
The screen memories presented by the patient in relation to her family (they were happy, they got along very well, her stepfather loved her as his own child, he got along perfectly with her sister who returned to the family in adolescence) highlight her immaturity, indicating the fact that if there were misunderstandings or conflicts within the family, the patient would not have been able to become aware of them, taking refuge in her religious beliefs. Her intention to leave home at a young age can be understood taking into consideration this interpretation, intention which can be regarded as a dissociative escape.

The patient also had such a dissociative fugue when she left the monastery where she lived to look for another monastery to join, a moment when she failed to realize her dissatisfaction and resolve the possibly existing conflicts with the other nuns. This behaviour can be taken from her mother. According to reports, she "ran away" from multiple events that were not in concordance with her beliefs. Firstly, she ran away from home from the mother that was physically abusing her, then she ran away from her own child that showed delicate health, moving to another city. Also, her relational experience, the fact that she had three marriages, proves the same dissociative behaviour pattern. The patient unconsciously adopted this mechanism of avoiding responsibilities and events that are inconsistent with her own conscious.

Also, the fact that her mother left her ill daughter in hospital and then she came back at eighteen years old causes the patient to run to a monastery to find her place, yielding her place in favour of her older sister. In the patient's imagination, her mother can love only one daughter, she considering herself redundant in her family's hierarchy.

In the structure of the patient's personality, the Oedipus Complex can be found, which could be the cause of her neuroses and anxieties felt by her. The unfulfilled relationship with her biological father and replacing him with her mother can provoke in her subconscious a feeling of frustration and unfulfillment. Oedipus Complex refers to erotic investments which one child makes with the parent of opposite sex, as well as hostile impulses towards the parent of the same sex. The purpose of this process or solving this phallic stage conflict which develops this complex consists of erasing the investments that exist regarding maternal and paternal figures, following the process of replacing through identification of the same-sex parent. During his professional activity, Freud identified two existential tendencies regarding neurotic people, especially the hostility towards the same-sex parent and the love for the opposite-sex parent. This explains why the author got to grouping these manifestations into the same complex. The simple existence of this complex does not imply developing a pathology, but represents a normal stage in one infant's psychological development. It is considered a pathology only when an infant's conflict remains unsolved. In patient's case, this conflict is not unsolved, causing relational disfunctions with opposite-sex persons. Thus, the patient states that the abbot is "her best friend", being like a father to her. This projection is provoked by the deformed image of the father because the patient did not have a stable model for this family role. According to the abbot, the patient was obsessed with him, sending him a plethora of inappropriate messages at night, specific to a woman fixated for a man. The patient avoids certain events that she took part in. This fixation is not admitted by the patient, but there exists the interior conflict felt in sexual regards through her evasion of similar subjects.

According to Loewald (1979), this complex contains mechanisms like regression, introspection and sublimation of possession means characteristic to sexual compulsion. These forms of self-control vary in correlation with the development of experience levels and maturity. Given the fact that the patient is in a stage of immaturity, her inadequate and repressed behaviour is representing the most developed way in which she can express herself. By analysing the study made by Loewald (1979), it can be observed how the assumption or the responsibility affirmation and the authority of the descendant (which are taken from the ascendants) are provoking guilt in descendants within the oedipal conflict between generations. Thus, the rivalry is playing an important role in gaining authority, autonomy and in the distribution of the feeling of guilt. Therefore, the constant conflict between the patient and other nuns can be explained through the projection which she has over the nuns from the monastery. Thus, the patient is projecting her mother's profile in her image of the nuns. She develops an unconscious oedipal conflict between her and the statuses of the other women in monastery, relating herself to the abbot's profile.

At the time of her departure from the monastery, the patient claims that Reverend Mother accused her of going to "men bars". This projection developed by Reverend Mother over the patient turned out to be offensive for the latter, and at the same time illustrating a way the patient is fantasizing about life outside of the monastery.

The patient shows a behaviour of regression when she is reciting a poem from fifth grade at the ending of the interview. This might be interpreted as an immature way of proving herself. The poem is about a character named "Smarty". The patient claims that the verse seemed funny and that she loved it, showing an unconscious relation between the immature way she perceives herself and the symbolism of the poem. 


\section{SOURCES OF FUNDING}

This research received no specific grant from any funding agency in the public, commercial, or not-for-profit sectors.

\section{CONFLICT OF INTEREST}

The author have declared that no competing interests exist.

\section{ACKNOWLEDGMENT}

None.

\section{REFERENCES}

[1] American Psychiatric Association, DSM-5 Task Force. (2013). Diagnostic and statistical manual of mental disorders: DSM-5 $5^{\mathrm{TM}}$ (5th ed.). American Psychiatric Publishing, Inc.

[2] French, J. H., \& Shrestha, S. (2019). Histrionic personality disorder. In StatPearls [Internet]. StatPearls Publishing.

[3] ICD-10 The classification of mental and behavioural disorders. (2016), București: Editura Trei.

[4] Loewald, H. W. (1979). The Waning of the Oedipus Complex. Journal of the American Psychoanalytic Association, 27(4), 751-775. 